\title{
Trends in clinical trial registration in sub- Saharan Africa between 2010 and 2020: a cross-sectional review of three clinical trial registries
}

Bassey Edem ${ }^{1 *}$ (D) Chukwuemeka Onwuchekwa ${ }^{1}$ D, Oghenebrume Wariri ${ }^{1}$ (D), Esin Nkereuwem ${ }^{1}$ (D), Oluwatosin O. Nkereuwem ${ }^{1}$ (D) and Victor Williams ${ }^{2}$ (D)

\begin{abstract}
Objective: Prospective registration of clinical trials is an ethical, scientific, and legal requirement that serves several functions, including minimising research wastage and publication bias. Sub-Saharan Africa (SSA) is increasingly hosting clinical trials over the past few years, and there is limited literature on trends in clinical trial registration and reporting in SSA. Therefore, we set out to determine the trends in clinical trials registered in SSA countries between 2010 and July 2020.

Methods: A cross-sectional study design was used to describe the type of clinical trials that are conducted in SSA from 1 January 2010 to 31 July 2020. The registries searched were ClinicalTrials.gov (CTG), the Pan African Clinical Trials Register (PACTR), and the International Standard Randomized Controlled Trial Number (ISRCTN). Data were extracted into Excel and imported into STATA for descriptive analysis.

Results: CTG had the highest number of registered trials at 2622, followed by PACTR with 1501 and ISRCTN with 507 trials. Trials were observed to increase gradually from 2010 and peaked at 2018-2019. Randomised trials were the commonest type, accounting for at least $80 \%$ across the three registries. Phase three trials investigating drugs targeted at infections/infestations were the majority. Few completed trials had their results posted: 58\% in ISRCTN and $16.5 \%$ in CTG, thus suggesting reporting bias.
\end{abstract}

Conclusion: Despite the gradual increase in clinical trials registered during the period, recent trends suggest a drop in the number of trials registered across the region. Strengthening national and regional regulatory capacity will improve clinical trial registration and minimise reporting bias in completed clinical trials.

Keywords: Clinical trial registration, Sub-Saharan Africa

\footnotetext{
* Correspondence: basseyeedem@gmail.com

${ }^{1}$ Department of Vaccines and Immunity, Medical Research Council (MRC)

Unit The Gambia at the London School of Hygiene and Tropical Medicine,

Fajara, The Gambia

Full list of author information is available at the end of the article
}

C C The Author(s). 2021 Open Access This article is licensed under a Creative Commons Attribution 4.0 International License, which permits use, sharing, adaptation, distribution and reproduction in any medium or format, as long as you give appropriate credit to the original author(s) and the source, provide a link to the Creative Commons licence, and indicate if changes were made. The images or other third party material in this article are included in the article's Creative Commons licence, unless indicated otherwise in a credit line to the material. If material is not included in the article's Creative Commons licence and your intended use is not permitted by statutory regulation or exceeds the permitted use, you will need to obtain permission directly from the copyright holder. To view a copy of this licence, visit http://creativecommons.org/licenses/by/4.0/ The Creative Commons Public Domain Dedication waiver (http://creativecommons.org/publicdomain/zero/1.0/) applies to the data made available in this article, unless otherwise stated in a credit line to the data. 


\section{Background}

Clinical trial registration involves prospectively registering a clinical trial's details in a publicly accessible, webbased database called a clinical trial registry [1]. Historically, clinical trial registration was mandated by the World Medical Association in its 1967 Declaration of Helsinki [2]. The Declaration had, among other things, called for the prospective registration of clinical trials in a publicly accessible platform. It equally tasked collaborators such as investigators, sponsors, and others to have a mechanism to disseminate the results of clinical trials ethically, irrespective of the results. Clinical trial registration is both an ethical and legal obligation in the conduct of clinical trials [3]. The registration of clinical trials serves many purposes, such as providing a publicly accessible repository of trials that may help patients and the public decide which to enrol in, avoid needless repetition of trials, and minimise publication bias by forestalling the selective reporting of research outcomes [4, 5]. Clinical trial data submitted for registration must contain a minimum of twenty-four essential items for the Trial Registration Data Sets (TRDS) to be considered fully registered [6].

Two notable events have positively impacted clinical trial registration. In 2005, the International Committee of Medical Journal Editors (ICMJE) made the prospective registration of clinical trials a requirement for accepting manuscripts reporting study results for publication [7]. Also, in 2006, the World Health Organization (WHO) established the International Clinical Trials Registry Platform (ICTRP) to provide a single point for scientists, patients, and the public to access global clinical trials. In the WHO registry network, registries are classified as primary and partner registries [8]. The primary registries comply with the WHO- and ICMJEspecific criteria for content, quality and validity, accessibility, unique identification, technical capacity, and administration. In addition to complying with some of these requirements, partner registries are not required to have a regional or national mandate, may or may not be managed by a not-for-profit organisation, and accept prospective registration. Currently, there are 17 primary registries in the WHO's ICTRP network [8].

Although studies have demonstrated an increasing number of clinical trials conducted in Africa, as evidenced by the rising number of trials registered in the continent [6, 7], it is still far less than the rest of the world. Recent estimates in a study that utilised the ICTRP database found that Africa recorded the least registered interventional clinical trials $(2.3 \%)$ in the WHO ICTRP database from 2004 to 2013, compared to North America, Europe, and Asia that was 35.2, 35.2, and $25.0 \%$, respectively. Others were Oceania at $6 \%$ and Latin America and the Caribbean with 4.3\% [9].
Sub-Saharan Africa (SSA), a region comprising 48 countries and a population of 1.107 billion people as of 2019 [10], accounts for a large proportion of the global burden of infectious and non-communicable diseases (NCDs) [11]. Over the past decade, the region has been the site of several groundbreaking research into interventions for preventing and treating infectious diseases such as pneumonia, and malaria, $[12,13]$. These interventions have not only improved disease control but have transformed global health. There is, however, limited evidence on the types of clinical trials registered in the region compared to other world regions. Our objective, therefore, was to describe the trends in clinical trial registration in the SSA region over the past decade by reviewing three registries where trials conducted on the continent are commonly registered.

\section{Methods}

\section{Data sources}

This study utilised data obtained from ClinicalTrials.gov (CTG), the Pan African Clinical Trial Registry (PACTR), and the International Standard Randomized Controlled Trial Number (ISRCTN) registries. Established in 2000, CTG (https://www.ClinicalTrials.gov/ct2/about-site/ background) is a collaborative effort of the US National Institute of Health (NIH) and the Food and Drug Administration (FDA). It serves as a resource to provide accessible information on publicly and privately funded research involving human subjects [14]. The PACTR, on the other hand, is a regional registry of clinical trials conducted within Africa. It was established in 2007 as the AIDS, TB, and malaria clinical trial registry, and by 2009 , its mandate had broadened to include clinical trials in all fields [15]. Lastly, the ISRCTN was launched in 2000 and serves as a primary registry for all types of intervention studies involving human subjects [16]. We performed a preliminary analysis of the source registry for study records conducted in SSA, available in the WHO's ICTRP, and found that the CTG, PACTR, and ISRCTN together represent about $88 \%$ of ICTRP data source (analysis not shown), hence, our decision to utilise records in these three registries. All three registries are part of the WHO ICTRP and are publicly accessible, with both PACTR and ISRCTN designated as primary registries [8].

\section{Search and inclusion}

We conducted a basic search of the CTG, PACTR, and ISRCTN on 15 August 2020, 18 August 2020, and 9 September 2020, respectively. We searched by country for each registry and identified all clinical trials on human subjects registered between 1 January 2010 and 31 July 2020. We decided to include the first half of 2020 in our analysis to explore how the clinical trial landscape 


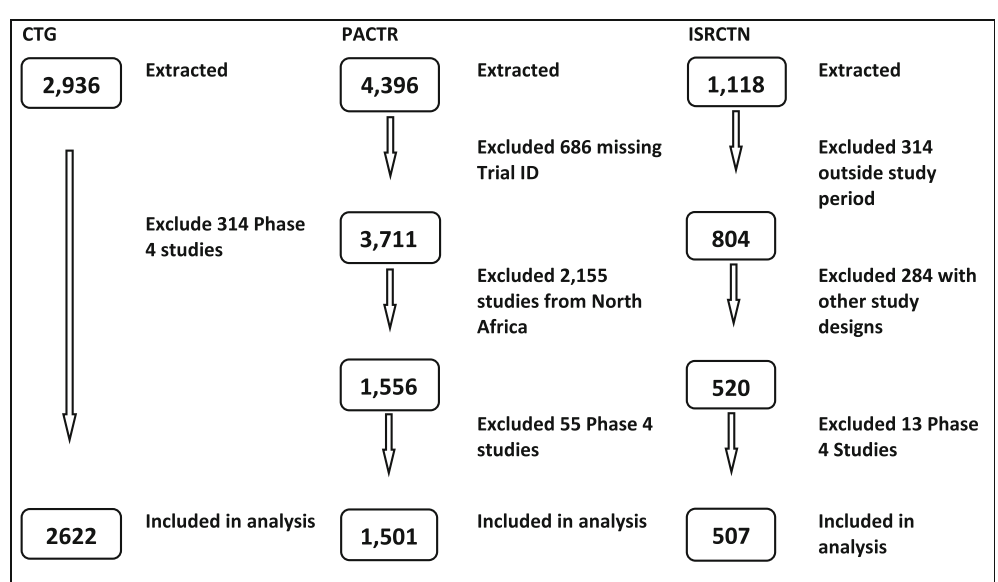

Fig. 1 Flow chart describing data extraction by registry. The three registries had varying levels of flexibility during data extraction. With CTG, it was possible to apply filters directly for countries in SSA for the study period. PACTR and ISRCTN had limited flexibility, and components of the data which was not required are excluded as shown in the flow chart

has fared during the COVID-19 pandemic. Trials were eligible if they included participants from an SSA country. Only interventional studies were eligible to be included in this research. We excluded observational, post-licencing, and impact evaluation studies. For all three registries, we re-categorised the data as presented. The flowchart in Fig. 1 describes our search results and which studies were eligible across all three registries.

\section{Data management}

We downloaded the records from the registries in separate Excel files for each eligible country. The registries had a maximum number of records that could be extracted at a time. To overcome this challenge, records were extracted monthly, quarterly, or annually depending on the number of records until all the study period records were extracted. The extracted country records from each registry were subsequently cleaned and merged into a single dataset for analysis. We extracted data on unique trial identifiers, trial registration history, the status of the trial, participant description, trial administration, publication status, and study sponsors for each registered trial. Details of complete data items extracted are presented in Table 1.

In all three registries, study sponsors were entered as free text. Thus, we identified the various study sponsors by extracting and grouping the common recurring themes such as individuals' titles, university/faculty/ school/academic institutions, hospital/clinic/medical centre, or research institute/organisation in the descriptive text. We performed a similar data management process for study design and the age of study participants in CTG. All three registries had varying completeness levels as specific variables which were either absent or had $>90 \%$ missing depending on the registry were excluded from the analysis. Individual observations missing unique identification numbers were dropped, and data items were described relative to the total number of trials with unique study identification for the study period. We performed data management with Excel and STATA 15 (STATA Corp., College Station, TX).

\section{Analysis}

A descriptive analysis using tables and figures was used to examine the trends in clinical trial registration in SSA

Table 1 Data items extracted for all trials

Primary registry ID
Study title
Countries of recruitment
Date of trial registration
Timing of registration (relative to study start date)
Study start date
Recruitment start date
Expected date of study completion (or end)
Study status
Study phase
Primary study design
Health condition addressed by the trial
Type of intervention studied
Participant age group
Participant gender
Type of participant studied ${ }^{\mathrm{a}}$
Publication of results
Publication of trial protocol
Study sponsor

${ }^{\mathrm{a}}$ Available only in ISRCTN 
Table 2 Summary characteristics of trials in the three registries

\begin{tabular}{l} 
Description \\
\hline Number of trials registered \\
Number of studies completed \\
Number of completed with \\
Overall trial status \\
Completed \\
Ongoing/active \\
Not yet recruiting/pending \\
Recruiting \\
Stopped/terminated \\
Suspended \\
Withdrawn \\
Other/unknown
\end{tabular}

\section{Prospective/retrospective}

Prospectively registered

Retrospectively registered

\section{Study design}

\section{Allocation}

Randomised

Non-randomised

N/A

\section{Intervention model}

Parallel assignment

Single group assignment

Cross-over assignment

Factorial assignment

Sequential assignment

None (open label)

\section{Masking}

None

Single

Double

Triple

Quadruple

Phase

$\begin{array}{ll}\text { Not applicable } & 149(29.4) \\ \text { Not specified } & 10(2.0) \\ \text { Phase 0/early phase 1 } & - \\ \text { Phase I } & 4(0.8) \\ \text { Phase I/II } & 3(0.6) \\ \text { Phase II } & 27(5.3) \\ \text { Phase II/II } & 10(2.0) \\ \text { Phase III } & 57(11.2) \\ \text { Phase III/IV } & 2(0.4)\end{array}$

ISRCTN, $\boldsymbol{N}$ (\%)

507

$386(76.1)$

$224(44.2)$

386 (76.1)

$103(20.3)$

$15(3.0)$

$49(9.7)$

$2(0.4)$

$16(3.2)$

$228(45.0)$

$279(55.0)$

$450(88.8)$

$50(9.9)$

$3(0.6)$

$2090(79.7)$

$224(8.5)$

$300(11.4)$

1919 (73.2)

$414(15.8)$

$113(4.3)$

$107(4.1)$

$60(2.3)$

$7(0.3)$

$1577(60.1)$

$348(13.3)$

$224(8.5)$

146 (5.6)

$312(11.9)$

$1426(54.4)$

$11(0.4)$

169 (6.4)

109 (4.2)

$371(14.1)$

113 (4.3)

$423(16.1)$
PACTR, $\boldsymbol{N}(\%)$

1501

$40(2.6)$

443 (29.5)

324 (21.6)

$-$

$-$

-

\section{9 (87.9) \\ 175 (11.7) \\ $7(0.5)$}

1003 (66.8)

$49(3.3)$

95 (6.3)

$341(22.9)$

-

1301 (86.7)

$43(2.9)$

$43(2.9)$

$52(3.5)$

$60(4.0)$ 
Table 2 Summary characteristics of trials in the three registries (Continued)

\begin{tabular}{|c|c|c|c|}
\hline Description & ISRCTN, $N$ (\%) & CTG, $N(\%)$ & PACTR, $N(\%)$ \\
\hline \multicolumn{4}{|l|}{ Sponsor } \\
\hline University & $262(51.7)$ & $1618(61.7)$ & $496(33.3)$ \\
\hline Industry/INGOa & $16(3.2)$ & $288(11.0)$ & $27(1.8)$ \\
\hline Research institution & $105(20.7)$ & $1190(45.4)$ & $164(10.9)$ \\
\hline Government & $56(11.0)$ & & \\
\hline Charity & $38(7.5)$ & & \\
\hline Hospital/clinic & $16(3.2)$ & $437(16.7)$ & $94(6.3)$ \\
\hline Private individuals & & & $116(7.7)$ \\
\hline \multicolumn{4}{|l|}{ Sex } \\
\hline Both & $413(81.5)$ & $1961(74.8)$ & $1074(71.6)$ \\
\hline Female & $88(17.4)$ & $553(21.1)$ & $360(24.0)$ \\
\hline Male & $5(1.0)$ & $108(4.1)$ & $67(4.5)$ \\
\hline \multicolumn{4}{|c|}{ Target number of participants } \\
\hline Min, $\max ^{a}$ & $0,2,000,000$ & $0,650,000$ & $0,497,379$ \\
\hline Mean $(S D)^{a}$ & $73,780(338,098)$ & $5298(32,513)$ & $1322(15,010)$ \\
\hline Median $(\mathrm{IQR})^{\mathrm{a}}$ & $902(2,004,000)$ & $348(1,001,233)$ & $140(60,400)$ \\
\hline
\end{tabular}

INGO international non-governmental organisations

${ }^{a}$ This will not equal total completed trials because sponsor type was obtained by extracting the common theme from a free text, indicating the possibility of a double count

for the period under review. Summary statistics of specific items were described for the three registries using proportions (Table 2). We presented a summary of completed trials with results for all countries in SSA in the three registries in a table (Appendix I). We also illustrated the total number of trials registered by year in each registry in a line graph. The top ten countries with the highest number of entries for each registry and the trials' results status were also presented. A sub-analysis of data from CTG to identify the commonest intervention type registered and the primary purpose of the study was done (Appendix II).

\section{Results}

\section{Summary of search results}

Table 2 summarises the characteristics of different items from each of the registries under review. Different registries reported standardised characteristics using different approaches with a varying level of completeness for each item. CTG had the highest number of registered trials at 2622, followed by PACTR at 1501 and ISRCTN with 507 trials. Only the ISRCTN contained information on the timing of trial registration, that is, whether a trial is prospectively or retrospectively registered. Of the 507 clinical trials reported, $45 \%$ were prospectively registered, while $55 \%$ were registered retrospectively. ISRC $\mathrm{TN}$ had the highest proportion of completed trials, and greater than $80 \%$ of trials in the three registries were randomised. The parallel assignment was the commonest intervention model as shown by CTG and PACTR, which documented this information with cross-over, single group, and factorial featuring prominently.

Masking was not done in about $60 \%$ of trials as reported by CTG only, and where present, single (13.3\%) and quadruple (12\%) masking were the preferred methods. Data on the trials' phase were complete in CTG and PACTR (100\%), while ISRCTN had missing data in 245 (48\%) of 507 included trials. Over 50\% of reported trials had their clinical trial phase classified as "not applicable" or "not specified" from the available data. In PACTR, this proportion was higher at $86 \%$, and trials in early phase 1 to phase III ranged from 0.42 to $16.1 \%$.

Only the ISRCTN reported on disease conditions that the trials targeted (Appendix III). Most of the registered trials involved interventions addressing infectious diseases and infestations (42.5\%). A further 12\% concerned maternal and newborn conditions and $6.5 \%$ were related to mental and behavioural conditions. No specific disease condition was mentioned in 55 of the identified trials. Top sponsors from the three registries were universities or academic institutions, closely followed by research organisations. The three registries did not have variables describing the countries sponsors of the study were based to enable analysis. However, a review of the ISRCTN Registry (with few entries) shows that $6-50 \%$ of studies had sponsors from the countries the studies were conducted in the top ten countries. This is presented in Table 3. This process was not possible for CTG, but a review of the registry, however, shows that most of the sponsors are US-based with a country-based sponsor or 
Table 3 Summary of top ten countries with same country sponsor

\begin{tabular}{llll}
\hline Country & Number of studies & Same country sponsor & \% Same country sponsor \\
\hline Ghana & 22 & 11 & $50 \%$ \\
South Africa & 66 & 32 & $48 \%$ \\
Nigeria & 36 & 16 & $44 \%$ \\
Zambia & 24 & 9 & $38 \%$ \\
Kenya & 47 & 15 & $32 \%$ \\
Uganda & 82 & 18 & $22 \%$ \\
Cote d'Ivoire & 14 & 3 & $21 \%$ \\
Malawi & 43 & 5 & $12 \%$ \\
Tanzania & 41 & 5 & $12 \%$ \\
Ethiopia & 18 & 1 & $6 \%$ \\
\hline
\end{tabular}

collaborator. Similarly, this analysis was not feasible with PACTR, but the authors observed the portal is presently being updated and may enable this analysis in future.

Most studies targeted adults of both sexes (> 70\%). Still, limitations with the classification of the age of participants across the three registries made it impossible to properly categorise participants' age. Only ISRCTN provided information describing the type of study participants, and the majority were patients at 66\% (Appendix IV).

\section{Top countries registering trials}

A review of the three registries indicated that certain countries had more trials registered than other countries in the region. Figure 2 below shows the top ten countries with the highest number of registered trials by each registry. South Africa, Uganda, Kenya, and Nigeria accounted for most of the registered trials, while other major trial sites include Malawi, Tanzania, Zambia, Ghana, Ethiopia, and Cameroon. ClinicalTrial.gov and PACTR were the preferred registries.

\section{The trend in trial registration}

Between 2010 and 2019, we observed a steady increase in the number of trials registered in CTG, with 322 trials registered in 2019 compared with 164 in 2010. Similarly, the number of trials registered in PACTR increased between $2010(n=36)$ and $2018(n=284)$, with a decline to 251 in 2019 (data as of 31 July 2020). The number of registered trials on ISRCTN was lowest in $2010(n=30)$, peaking in $2017(n=61)$, and with a slight dip in 2018

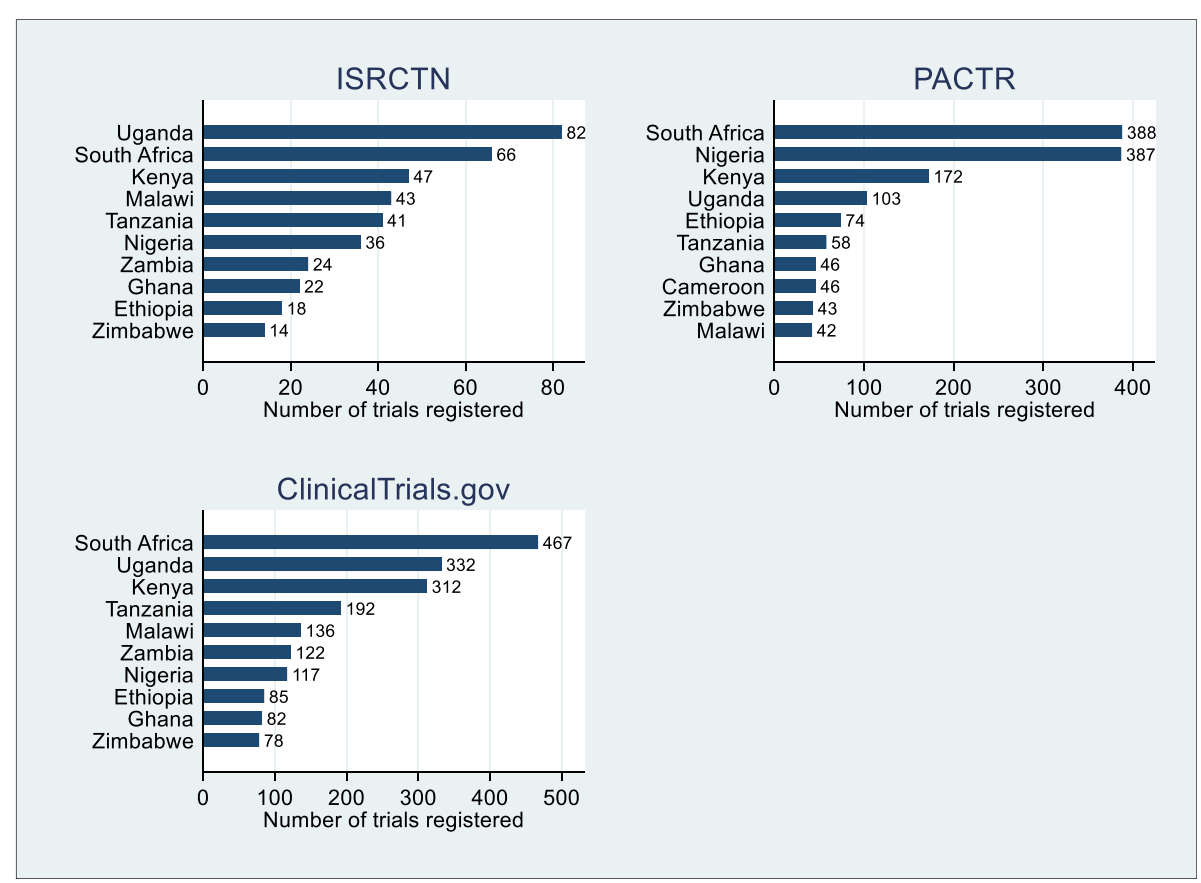

Fig. 2 Top ten countries where the highest numbers of trials are registered in sub-Saharan Africa between 2010 and 2020 


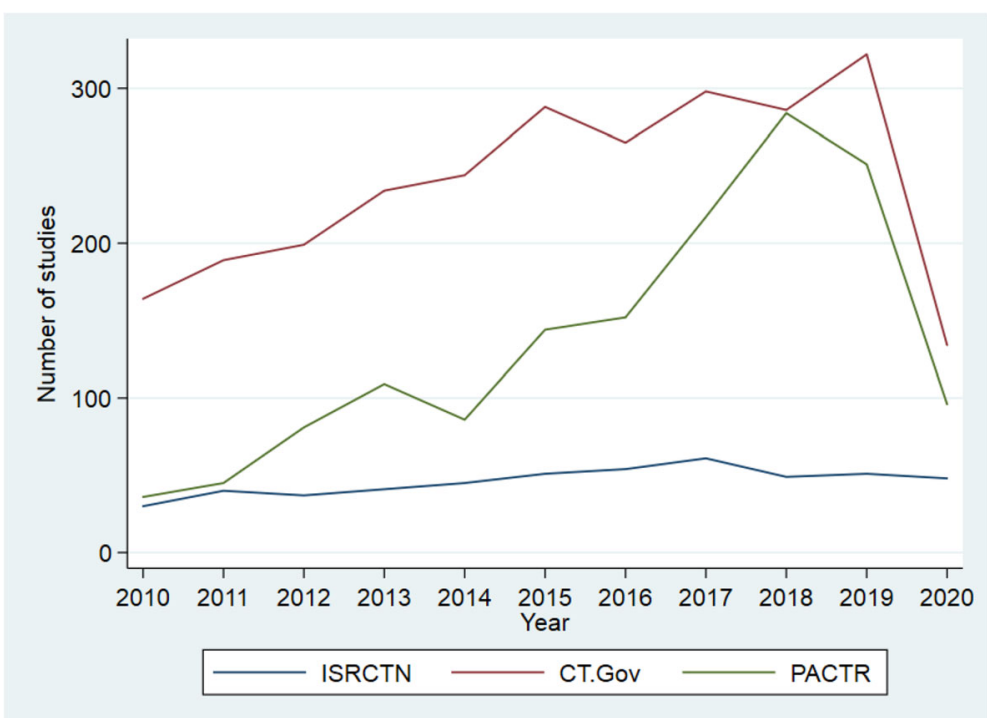

Fig. 3 Trends in clinical trial registration in sub-Saharan Africa between 2010 and 2019 across three registries

and 2019. Between January and July of 2020, the number of trials registered on ISRCTN is similar to the total number registered in the preceding year. Meanwhile, the numbers registered in the same period in PACTR $(n=$ $108)$ and CTG $(n=134)$ were 40 and $42 \%$ of the numbers reported in the preceding year, respectively (Fig. 3).

\section{Intervention type and purpose of the study}

Data on intervention type and the primary purpose of studies was available only in ClinicalTrials.gov (Appendix II). The commonest intervention type was drug (31.9\%) closely followed by behavioural interventions at $20 \%$. Other prominent types of intervention documented were biological (11\%), device (6.7\%), and dietary supplement (5.7\%). Treatment accounted for the highest primary purpose of conducted trials at $39.2 \%$. This was closely followed by prevention (33.3\%), and health services research (9.4\%). Less significant reasons for conducting trials were screening $(1.1 \%)$ and device feasibility $(0.2 \%)$.

\section{Publication of trial results}

Of the 1469 completed trials registered on CTG, only $243(16.5 \%)$ were reported as having results, while 224 of the 386 completed trials registered on ISRCTN had posted a summary of the results (58.0\%) (Fig. 4). PACTR registered 40 trials with results but did not provide

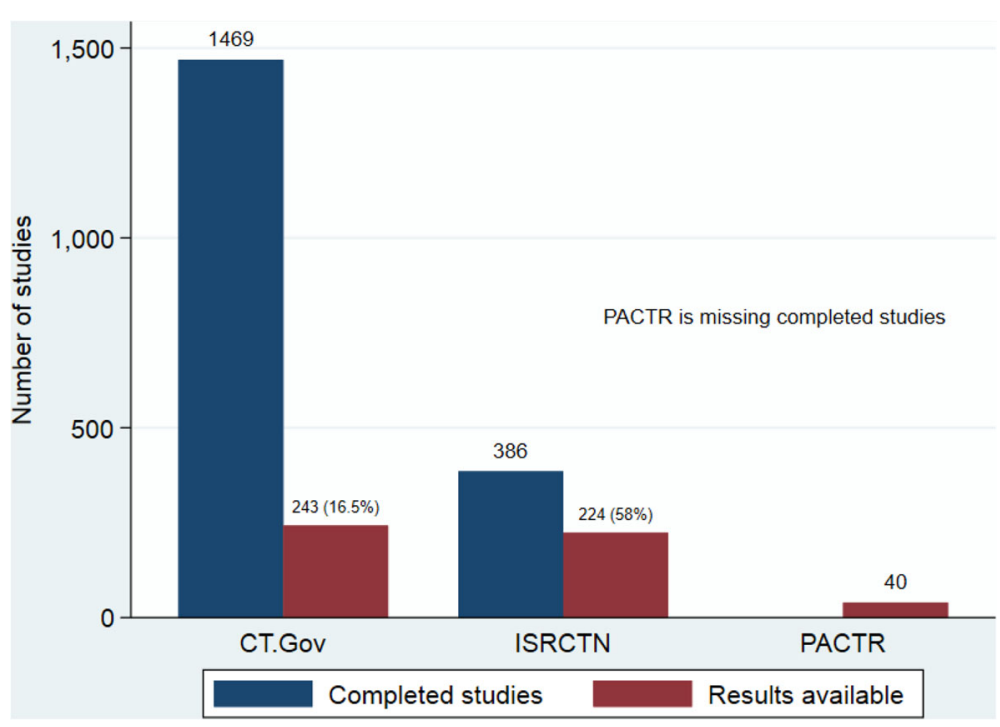

Fig. 4 Completed clinical trials with results by registry 
Table 4 Summary of sponsors with published results

\begin{tabular}{|c|c|c|c|c|c|c|c|c|}
\hline \multirow{2}{*}{$\begin{array}{l}\text { Sponsor } \\
\text { category }\end{array}$} & \multicolumn{4}{|c|}{ ISRCTN $(N=507)$} & \multicolumn{4}{|c|}{ CTG $(N=2262)$} \\
\hline & $\begin{array}{l}\text { Registered } \\
\text { (N) }\end{array}$ & $\begin{array}{l}\text { Complete } \\
\text { (n) }\end{array}$ & $\begin{array}{l}\text { Published } \\
(n)\end{array}$ & $\begin{array}{l}\text { Proportion of } \\
\text { completed with results } \\
\text { (\%) }\end{array}$ & $\begin{array}{l}\text { Registered } \\
\text { (N) }\end{array}$ & $\begin{array}{l}\text { Complete } \\
\text { (n) }\end{array}$ & $\begin{array}{l}\text { Published } \\
(n)\end{array}$ & $\begin{array}{l}\text { Proportion of } \\
\text { completed with results } \\
(\%)\end{array}$ \\
\hline University & 262 & 183 & 108 & 59.0 & 1618 & 891 & 72 & 8.1 \\
\hline $\begin{array}{l}\text { Industry/ } \\
\text { INGO }^{\mathrm{a}}\end{array}$ & 16 & 15 & 6 & 40.0 & 288 & 165 & 30 & 18.2 \\
\hline $\begin{array}{l}\text { Research } \\
\text { institutions }\end{array}$ & 105 & 81 & 47 & 58.0 & 1190 & 605 & 104 & 17.2 \\
\hline Government & 56 & 51 & 28 & 54.9 & - & - & - & - \\
\hline Charity & 38 & 31 & 18 & 58.1 & - & - & - & - \\
\hline Hospital/clinic & 16 & 12 & 6 & 50.0 & 437 & 231 & 49 & 21.2 \\
\hline
\end{tabular}

aINGO international non-governmental organisations; this will not equal total completed trials because sponsor type was obtained by extracting the common theme from a free text, indicating the possibility of a double count

information on the total number of completed trials. A breakdown of completed trials with results by the country for each registry was analysed and presented as Appendix I.

We further explored the data to identify the proportion of completed trials with published results based on clinical trials' sponsors across the two registries with complete data (Table 4). Overall, CTG, which had more completed trials, had a lower proportion of completed trials with available results than ISRCTN. The proportion of completed trials with results ranged from 8.1 to $21.2 \%$ in CTG depending on the sponsor, while in ISRCTN, it was 50\% and slightly above depending on the sponsor except for industry which was $40 \%$.

\section{Discussion}

Since 2010, there has been some progress in the number of clinical trials registered in SSA. While we cannot account for the decline in clinical trial registration observed in ISRCTN and CTG from 2018 to 2019, a possible explanation for this may be that more trials are registered in other registries as the number of available registries at investigators' disposal increases. The consistency in the number of registered trials observed in the ISRCTN is suggestive of this. We did not observe a large difference in the number of registered clinical trials in the first half of 2020 compared to the preceding year, despite the increase in COVID-19 research. While much of the current focus of biomedical research has been on COVID-19 interventions, we identified only one clinical trial of a COVID-19 candidate vaccine registered in Africa. However, we believe this would improve as plans are underway to ensure Africa hosts more clinical trials of COVID-19 interventions. In fact, not only has a second COVID-19 vaccine trial commenced in Kenya but a consortium of African researchers and research institutions have been launched to facilitate the conduct of COVID-19related trials on the continent [17]. Also, considering that historically, the proportion of clinical trials registered in low- and middle-income countries (LMICs) lag behind high-income countries (HIC), and most SSA countries are LMICs. Despite our analysis being restricted to this region alone, our findings suggest the same trend compared to existing literature [9].

From our study, infections and infestations were the top health condition researched. Despite this data being available from only one registry (ISRCTN), it is a useful pointer that the trials conducted align with the region's health needs. A review of the PACTR performed 6 years after its launch revealed that infectious diseases were the leading condition researched on the African continent [18]. In contrast, in Egypt, which is not in sub-Saharan Africa, cancers were the most studied conditions [19]. Recent evidence suggests an epidemiological transition with NCDs becoming the leading source of morbidity and mortality on the continent [11], indicating a need to prioritise research into these conditions.

Study sponsors are mandated to summarise their study findings in the registry and disseminate them in peerreviewed publications to improve transparency $[20,21]$. Our study reveals that most of the clinical trials conducted in SSA go unreported, considering that CTG, which had the highest number of completed trials, had less than $20 \%$ of the trials reported. In contrast, more than half of those in the ISRCTN were reported. While there is limited literature on this important trend in SSA generally, a study found that about $48.6 \%$ of completed trials in the South African National Clinical Trials Register (SANCTR) were registered within a median time of 2 years of completion and the majority of the published trials were those with a positive outcome [22], revealing the possibility of publication bias. Our study relied solely on completed trials with results available in the study field and did not further verify if these studies have been 
published in peer-reviewed journals as was done in the South African study. Despite this difference in the methodology, we demonstrate that publication bias is a problem that needs to be addressed. However, study sponsors' failure to register trials and post summary outcomes of completed studies persists even with stringent regulatory authorities in developed countries [23, 24]. A study designed differently from ours found that about $15 \%$ of 439 trials were registered retrospectively, after the investigators may have observed some of the primary outcomes [25]. It is, however, noteworthy that investigators may opt to publish study results in journals rather than post them in the clinical trial registry or do either of these at different time intervals, as has been established in the literature [26, 27].

Research is unevenly distributed across the continent, with Uganda and South Africa accounting for over 50\% of the registered studies. These countries have wellestablished biomedical research capacity, which could explain the higher clinical trial output from these countries. Indeed, these countries host many of the major biomedical research institutions in sub-Saharan Africa, according to the SClimago institute ranking [28]. Due to their reputation, these high-ranking institutions are more likely to attract clinical trials and other types of research.

Our findings should, however, be interpreted with caution. Firstly, we analysed the data available in only three registries. Despite this limitation, we believe that our results give a realistic picture of clinical trial registration trends for the past decade in SSA. Our analysis of the data sources for the available trials in the WHO's ICTRP found that CTG, PACTR, and ISRCTN together represent about 88\% ICTRP data source (analysis not shown). They, therefore, provide an adequate representation of clinical trials registered from sub-Saharan Africa. Next, we did not deduplicate study records found in all three registries as each registry assigned a unique study identification number (id) to each trial. Consequently, individual study records could be found in one or more registries but with a different study id. Hence, analysing the records gives the unique advantage of presenting a snapshot of trial registration in SSA in any registry. Missing data across the submitted trials in the three registries may also have the potential to bias some of our findings. These range from fields that were completed as "unknown" or missing to others, such as the absence of trial status in the PACTR. For the latter, we were unable to estimate with certainty the proportion of completed trials in that registry that had results posted. The problem of incomplete trial datasets in registries has been highlighted [29, 30] and still remains a challenge across registries.
Also, despite existing regulations on prospective registration of clinical trials, some study sponsors fail to comply or only register their trials retrospectively [25, 31]. This impacts our study because we do not have a useful denominator for all the trials that have been conducted in Africa. Nevertheless, the records of the registries are useful and provide vital information required to improve the documentation of clinical trials in Africa. One outcome of our study, the proportion of completed clinical trials with results available, may be impacted by the "lag" time between completion of a trial and posting of results.

The various registries' quality control teams need to pay greater attention to the submitted entries and ensure complete, comparable, and verifiable records. This is vital as we noted a great variability in the information documented in the three registries. Ensuring similar data fields in registries will not only be beneficial to the public but will enable ease of comparability and analysis of such data that can inform policy formulation. Finally, we recommend assigning each clinical trial a unique code for registration across all clinical trial registries to enhance the de-duplication of study data across and within registries during analysis of such data.

A clinical trial authorisation is one of the core functions of National Regulatory Authorities (NRAs) and these agencies, although available in all but one African country, have limited capacity [32, 33]. However, several initiatives are in place to strengthen regulatory capacity across the African continent. Some of these are regional regulatory harmonisation initiatives, such as the African Medicines Regulatory Harmonization (AMRH) and African Vaccine Regulatory Forum (AVAREF) [34], and the North-South collaborative initiatives like the European and Developing Countries Clinical Trials Partnership (EDCTP). These initiatives would possibly impact not just the conduct of trials in SSA but also the prospective registration and subsequent posting of results of completed trials that is an international best practice.

\section{Conclusion}

Despite the highlighted limitations of our study, we have demonstrated an uneven but sustained rise in the number of clinical trials registered in SSA using the records in three clinical trial registries. This was, however, followed by a sharp decline between 2018 and 2019 . Phase three trials investigating drugs targeted at infections/infestations were the majority. In over half of the completed trials, study sponsors failed to summarise the trial outcomes as mandated by regulatory guidelines. Although regulatory capacity is limited across the continent, several ongoing initiatives aim to improve ethics and regulatory capacity in Africa. This, hopefully, will 
lead to an improvement in clinical trial conduct, registration, and publication of study results.

\section{Abbreviations}

CTG: ClinicalTrials.gov; ICTRP: International Clinical Trials Registry Platform; ISRCTN: International Standard Randomized Controlled Trial Number; LMICs: Low- and middle-income countries; NCDs: Non-communicable diseases; PACTR: Pan African Clinical Trials Register; SSA: Sub-Saharan Africa; WHO: World Health Organization

\section{Supplementary Information}

The online version contains supplementary material available at https://doi. org/10.1186/s13063-021-05423-1.

Additional file 1: Appendix I: Table 1. Summary of completed studies with results for all the countries. Appendix II. Intervention type and the primary purpose of study. Table $\mathbf{2}$. Intervention Type (CTG. ONLY). Table 3. Primary purpose of study (CTG ONLY). Appendix III: Figure 1. Disease type targeted by trials. Appendix IV: Figure 2. Type of Study Participants

\section{Authors' contributions}

BE conceived the idea for the study, analysed the data, developed the first draft, and critically reviewed all drafts of the manuscript. VM and EO obtained, analysed, and organised the data and contributed to the first draft of the paper. OW, EN, and ON participated in obtaining, organising, analysing, and interpreting the data and critically reviewed the final draft of the manuscript. All authors read and approved the final draft of the manuscript.

\section{Funding}

This research work did not benefit from any external funds. When conducting the research, the authors were employees of their respective affiliated institutions and received a salary. The affiliated organisations were not involved in the conceptualisation, conduct, analysis, or decision to publish this work.

\section{Availability of data and materials}

The datasets used and/or analysed during the current study are available from the corresponding author on reasonable request.

\section{Declarations}

Ethics approval and consent to participate

Not applicable

\section{Consent for publication}

Not applicable

\section{Competing interests}

The authors declare that they have no competing interests.

\section{Author details}

'Department of Vaccines and Immunity, Medical Research Council (MRC) Unit The Gambia at the London School of Hygiene and Tropical Medicine, Fajara, The Gambia. 'Unit of Epidemiology and Biostatistics, School of Public Health, University of the Witwatersrand, Johannesburg, South Africa.

Received: 18 February 2021 Accepted: 5 July 2021

Published online: 21 July 2021

\section{References}

1. International Committee of Medical Journal Editors. Clinical trials registration [Internet]. ICMJE. 2020 [cited 21 May 2020]. Available from: http://www. icmje.org/about-icmje/faqs/clinical-trials-registration/.

2. World Medical Association. WMA Declaration of Helsinki - ethical principles for medical research involving human subjects - WMA - The World Medical Association [Internet]. World Medical Association. [cited 11 Jun 2021].
Available from: https://www.wma.net/policies-post/wma-declaration-ofhelsinki-ethical-principles-for-medical-research-involving-human-subjects/.

3. US National Library of Medicine. History, policies, and laws [Internet]. Clinica ITrials.gov. 2020 [cited 17 Nov 2020]. Available from: https://www.clinicaltria Is.gov/ct2/about-site/history.

4. Chan AW, Hróbjartsson A, Haahr MT, Gøtzsche PC, Altman DG. Empirical evidence for selective reporting of outcomes in randomized trials: comparison of protocols to published articles. J Am Med Assoc. 2004; 291(20):2457-65. https://doi.org/10.1001/jama.291.20.2457.

5. ICMJE. Clinical trials [Internet]. [cited 17 Nov 2020]. Available from: http:// www.icmje.org/recommendations/browse/publishing-and-editorial-issues/ clinical-trial-registration.html.

6. World Health Organization. International Clinical Trials Registry Platform (ICTRP) | WHO data set [Internet]. WHO. World Health Organization; 2020 [cited 17 Oct 2020]. Available from: http://www.who.int/ictrp/network/prima ry/en/.

7. International Committee of Medical Journal Editors. Clinical trial registration: a statement from the International Committee of Medical Journal Editors. N Engl J Med. 2004;1250-1. Available from: https://www.nejm.org/userimages/ ContentEditor/1274983032046/ClinicalTrialReg.pdf.

8. World Health Organization. International Clinical Trials Registry Platform (ICTRP) | primary registries [Internet]. WHO. World Health Organization; 2020 [cited 18 Oct 2020]. Available from: http://www.who.int/ictrp/network/primary/en/.

9. Viergever RF, Li K, Roderik D, Viergever F. Trends in global clinical trial registration: an analysis of numbers of registered clinical trials in different parts of the world from 2004 to 2013. BMJ Open. 2015;5:e008932 Available from: http://bmjopen.bmj.com/.

10. The World Bank. Population, total - sub-Saharan Africa | data [Internet]. 2019 [cited 22 Oct 2020]. Available from: https://data.worldbank.org/indicator/SP. POP.TOTL?locations=ZG

11. Gouda HN, Charlson F, Sorsdahl K, Ahmadzada S, Ferrari AJ, Erskine H, et al. Burden of non-communicable diseases in sub-Saharan Africa, 1990-2017: results from the Global Burden of Disease Study 2017. Lancet Glob Heal. 2019;7(10):e1375-87. https://doi.org/10.1016/S2214-109X(19)30374-2.

12. Clarke E, Bashorun AO, Okoye M, Umesi A, Badjie Hydara M, Adigweme I, et al. Safety and immunogenicity of a novel 10-valent pneumococcal conjugate vaccine candidate in adults, toddlers, and infants in The Gambia-results of a phase 1/2 randomized, double-blinded, controlled trial. Vaccine. 2020;38(2): 399-410. https://doi.org/10.1016/j.vaccine.2019.08.072.

13. Guerra Mendoza $Y$, Garric E, Leach A, Lievens M, Ofori-Anyinam O, Pirçon J$Y$, et al. Human vaccines \& immunotherapeutics safety profile of the RTS,S/ AS01 malaria vaccine in infants and children: additional data from a phase III randomized controlled trial in sub-Saharan Africa. 2019; Available from: https://doi.org/10.1080/21645515.2019.1586040.

14. US National Library of Medicine. ClinicalTrials.gov background [Internet] ClinicalTrials.gov. 2020 [cited 2020 Nov 17]. Available from: https://www. clinicaltrials.gov/ct2/about-site/background.

15. Pan African Clinical Trial Registry. History of PACTR [Internet]. PACTR. 2020 [cited 2020 Nov 17]. Available from: https:/pactr.samrc.acza/PACTRHistory.aspx

16. BMC. ISRTCN registry [Internet]. 2020 [cited 2020 Nov 17]. Available from: http://www.isrctn.com/page/about.

17. Makoni M. COVID-19 vaccine trials in Africa. Lancet Respir Med. 2020;8(11): e79-80. https://doi.org/10.1016/S2213-2600(20)30401-X

18. Abrams A, Siegfried N. The Pan African Clinical Trials Registry: year one data analysis of the only African member of the World Health Organization Network of Primary Registries. J Evid Based Med. 2010;3(4):195-200. https:// doi.org/10.1111/j.1756-5391.2010.01099.x Available from: https://pubmed. ncbi.nlm.nih.gov/21349070/.

19. Zeeneldin AA, Taha FM. The Egyptian clinical trials' registry profile: analysis of three trial registries (International Clinical Trials Registry Platform, PanAfrican Clinical Trials Registry and clinicaltrials.gov). J Adv Res. 2016;7(1):3745. https://doi.org/10.1016/j.jare.2015.01.003.

20. NIH. FDAAA 801 and the final rule - ClinicalTrials.gov [Internet]. [cited 13 Jan 2021]. Available from: https://clinicaltrials.gov/ct2/manage-recs/fdaaa.

21. National Institute for Health Research. NIHR policy on clinical trial registration and disclosure of results [Internet]. NIHR. 2019 [cited 13 Jan 2021]. Available from: https://www.nihr.ac.uk/documents/nihr-policy-onclinical-trial-registration-and-disclosure-of-results/12252.

22. Sibanda M, Sibanda M, Summers RS, Meyer JC. Publication trends of clinical trials performed in South Africa. South African Med J. 2016;106(5):519-23. https://doi.org/10.7196/SAMJ.2016.v106i5.9952. 
23. European Medicines Agency. Posting of clinical trial summary results in European Clinical Trials Database (EudraCT) to become mandatory for sponsors as of 21 July 2014 | European Medicines Agency [Internet]. 2014 [cited 19 Jan 2021]. Available from: https://www.ema.europa.eu/en/news/ posting-clinical-trial-summary-results-european-clinical-trials-database-eudra ct-become-mandatory.

24. National Institute for Health. FDAAA 801 and the final rule - ClinicalTrials.gov [Internet]. [cited 19 Jan 2021]. Available from: https://clinicaltrials.gov/ct2/ma nage-recs/fdaaa.

25. Gopal AD, Wallach JD, Aminawung JA, Gonsalves G, Dal-Ré R, Miller JE, et al. Adherence to the International Committee of Medical Journal Editors' (ICMJE) prospective registration policy and implications for outcome integrity: a cross-sectional analysis of trials published in high-impact specialty society journals. Trials. 2018;19(1):448 [cited 19 Jan 2021] Available from: https://pubmed.ncbi.nlm.nih.gov/30134950/.

26. Goldacre B, Devito NJ, Heneghan C, Irving F, Bacon S, Fleminger J, et al. Compliance with requirement to report results on the EU Clinical Trials Register: cohort study and web resource. BMJ. 2018;362:3218. https://doi. org/10.1136/bmj.k3218 [cited 12 Jun 2021].

27. Miller JE, Korn D, Ross JS. Clinical trial registration, reporting, publication and FDAAA compliance: a cross-sectional analysis and ranking of new drugs approved by the FDA in 2012. BMJ Open. 2015;5(11):e009758.

28. SCImago. SCIMAGO institutions ranking [Internet]. 2020 [cited 2020 Nov 17]. Available from: https://www.scimagoir.com/rankings.php?sector=Hea Ith\&country=Africa\&ranking=Research\&year $=2014$.

29. Viergever RF, Karam G, Reis A, Ghersi D. The quality of registration of clinical trials: still a problem. PLoS One. 2014;9(1):12-20. https://doi.org/10.1371/ journal.pone.0084727.

30. Viergever RF, Ghersi D. The quality of registration of clinical trials. PLoS One. 2011;6(2):e14701.

31. Loder E, Loder S, Cook S. Characteristics and publication fate of unregistered and retrospectively registered clinical trials submitted to the BMJ over 4 years. BMJ Open. 2018;8(2):e020037 [cited 2021 Jan 19] Available from: /pmc/articles/PMC5829901/?report=abstract.

32. Ndomondo-Sigonda M, Miot J, Naidoo S, Dodoo A, Kaale E. Medicines regulation in Africa: current state and opportunities. Pharmaceut Med. 2017; 31(6):383-97. https://doi.org/10.1007/s40290-017-0210-x.

33. Ndomondo-Sigonda M, Miot J, Naidoo S, Ambali A, Dodoo A, Mkandawire $H$. The African medicines regulatory harmonization initiative: progress to date. Med Res Arch. 2018;6(2):1-15 Available from: http://journals.ke-i.org/ index.php/mra/article/view/1668.

34. World Health Organization. African Vaccine Regulatory Forum (AVAREF) WHO | Regional Office for Africa [Internet]. WHO. 2020 [cited 13 Jan 2021]. Available from: https:/www.afro.who.int/health-topics/immunization/avaref.

\section{Publisher's Note}

Springer Nature remains neutral with regard to jurisdictional claims in published maps and institutional affiliations.

Ready to submit your research? Choose BMC and benefit from:

- fast, convenient online submission

- thorough peer review by experienced researchers in your field

- rapid publication on acceptance

- support for research data, including large and complex data types

- gold Open Access which fosters wider collaboration and increased citations

- maximum visibility for your research: over $100 \mathrm{M}$ website views per year

At BMC, research is always in progress.

Learn more biomedcentral.com/submissions 